\title{
Cholesterol Oxides Accumulate in Human Cataracts
}

\author{
HENRIQUE GIRÃO, MARIA C. MOTA, JOSẼ RAMALHO AND PAULO PEREIRA* \\ Department of Ophthalmology and Visual Sciences, Biomedical Institute for Research in Light and Image, \\ Coimbra University Hospitals, Azinhaga de Sta Comba-Celas, 3000 Coimbra, Portugal
}

\author{
(Received Oxford 13 October 1997 and accepted in revised form 13 January 1998)
}

\begin{abstract}
Human lens membranes contain the highest cholesterol content of any known biological membrane. Although cholesterol is prone to oxidation, the presence of its oxidation products in human cataract has not been shown before. This study was designed to investigate the presence of cholesterol oxides in human cataractous lenses. Human clear lenses $(n=48)$ were obtained from Coimbra University Hospital Eye Bank. Human cataracts $(n=54)$ were obtained by routine extracapsular surgery. Cholesterol oxides were isolated by solid-phase extraction on a $\mathrm{C}_{18}$ cartridge and quantified as TMS-ether derivatives by gas chromatography. The extraction procedure allows for an efficient recovery of the major cholesterol oxides, while retaining virtually all cholesterol. Exposure of membranes isolated from transparent human lenses to the free radical generator 2,2'-Azobis(2-amidinopropane) dihydrochloride (AAPH) produced $7 \alpha$ -

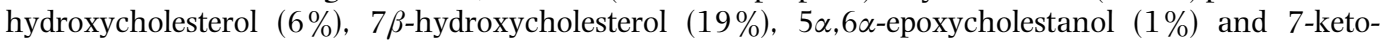
cholesterol $(74 \%)$ as major oxidation products. Cataractous lenses contained quantifiable amounts of $7 \beta$-hydroxycholesterol $\left(7 \cdot 3 \pm 0 \cdot 74 \mathrm{mmol} \mathrm{mol}^{-1}\right.$ cholesterol), 7 -ketocholesterol $\left(4 \cdot 2 \pm 0 \cdot 32 \mathrm{mmol} \mathrm{mol}^{-1}\right.$ cholesterol), $\quad 5 \alpha, 6 \alpha$-epoxycholestanol $\left(0 \cdot 9 \pm 0 \cdot 16 \mathrm{mmol} \mathrm{mol}^{-1}\right.$ cholesterol), $20 \alpha$-hydroxycholesterol

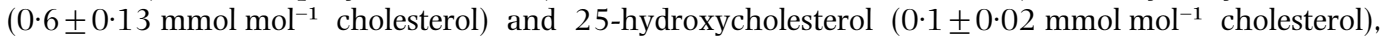
whereas clear lenses contained no detectable amounts of cholesterol oxides. We have shown, for the first time, that oxysterols accumulate in human cataracts. Although the total amount of oxidized cholesterol in cataracts is not likely to be high it may account for much of the membrane damage associated with cataract formation.

(C) 1998 Academic Press Limited

Key words: cataract; cholesterol oxidation; lens; lens membranes; oxysterols.
\end{abstract}

\section{Introduction}

Despite being generally considered as a multifactorial process, recent evidence has emphasized the participation of oxidative damage in human cataract formation (Spector, 1995). The lens is chronically exposed to radiation and upon ageing absorbs increasing amounts of ultra-violet light (Lerman, 1984). The lens contain sensitisers of singlet oxygen formation, which can damage and crosslink lens proteins (L'vova, Gorbunova and Abaeva, 1993; Lipman, Tripathi and Tripathi, 1988). The concentration of hydrogen peroxide in the aqueous humor is remarkably high (Sadeg et al., 1993; Spector and Garner, 1981) and further increases in patients with cataract (Spector and Garner, 1981) as do the levels of $\mathrm{H}_{2} \mathrm{O}_{2}$ in the lens itself (Bhuyan and Bhuyan, 1984). Extensive oxidation of proteins and accumulation of its oxidized metabolites have also been reported in cataractous lenses (Spector, 1984; Spector and Roy, 1978). Glutathione levels were shown to decrease during lens ageing and more so during cataract development (Kabadi, 1988; Kamei, 1993). The activity of antioxidant enzymes, particularly superoxide dismutase (Ohrloff and Hockwin, 1984), also

\footnotetext{
* For correspondence: Paulo Pereira, Department of Ophthalmology and Visual Sciences, Biomedical Institute for Research in Light and Image, Coimbra University Hospitals, Azinhaga de St ${ }^{a}$ Comba-Celas, 3000 Coimbra, Portugal.
}

decrease in cataractous lenses, accounting for the loss of antioxidant protection.

Lens membrane is a primary site of injury upon ageing in humans and may account for much of the tissue damage associated with cataract formation (Garner, 1981). Research on possible targets for oxidation on lens membranes has focused on phospholipid fatty acids and membrane proteins (Spector, 1995). Comparatively little attention has been given to cholesterol oxidation and to the wider implications of such process in the pathogenesis of cataract. The absolute amount of cholesterol in the lens is not remarkably high. However, as lens fibre cells lack intracellular organells, all cholesterol in the tissue is located in plasma membranes. Therefore, lens membranes contain the highest cholesterol content of any known biological membrane (Zelenka, 1984). Cholesterol distribution in the lens appears to follow an unusual pattern concentrating in the perinuclear region (Duindam et al., 1995). However the loss of phospholipid in the nuclear region leads to cholesterol ratios as high as $70 \%$ in the nucleus of some cataractous lenses (Zelenka, 1984).

As unsaturated lipids, cholesterol is prone to autoxidation initiated by most of the reactive oxygen species, with the possible exception of superoxide (Smith et al., 1977). The complete or partial structure of over 80 cholesterol oxidation products has already been elucidated (Smith, 1987; Smith, 1996). Some of these products have been found to possess adverse 
biological effects including cytotoxicity, angiotoxicity and mutagenecity (Sadeg et al., 1993; Smith and Johnson, 1989). Several hydroxylated cholesterol derivatives can also promote feedback inhibition of cholesterol biosynthesis at the 3-hydroxy-3-methylglutaryl coenzyme A (HMG-CoA) reductase level (Parish, Parish and Li, 1995). Significant oxidation of cholesterol and/or disturbance of cholesterol homeostasis may well result in cell injury compatible, at least partly, with the damage associated with cataract formation. The presence of cholesterol oxides in human cataracts has not been reported before, nor have the structural and functional implications of the accumulation of such oxides been examined in the lens (Cenedella, 1996).

\section{Materials and Methods}

\section{Chemicals}

Cholesterol and cholesterol oxide standards were purchased from Steraloids Inc. (Wilton, New Hampshire, U.K.). Bond Elut Sep-Pak C18 cartridges (500 mg) were obtained from Varian (Harbor City, CA, U.S.A.). N,O-bis(trimethylsilyl) trifluoroacetamide (BSTFA) was purchased from Merck (Darmstadt, Germany). 2,2'-Azobis(2-amidinopropane) dihydrochloride (AAPH) was obtained from Polysciences Inc. (Warrington, PA, U.S.A.). Unless otherwise indicated all other chemicals and reagents were of the highest purity available from either Sigma (St. Louis, MO, U.S.A.) or Merck (Darmstadt, Germany). All solvents were of chromatographic grade.

\section{Lenses}

Transparent human lenses $(n=48)$ were obtained from the Coimbra University Hospital Eye Bank. Lenses were removed within six hours of death and were immediately decapsulated. Human cataractous lenses $(n=54)$ were obtained from the Ophthalmology Service (Coimbra University Hospital) by routine extracapsular cataract surgery. In order to improve the homogeneity of the samples only totally opacified lenses were used in this study. This corresponds approximately to nuclear $(\mathrm{N})$, cortical $(\mathrm{Cx})$ and posterior subcapsular (PS) cataract with nuclear sclerosis (NS) ranging from 4-6 as defined by the Cooperative Cataract Research Group (CCRG) grade system (Chylack et al., 1983). All lenses were immediately transferred to sterile vials and stored at $-70^{\circ} \mathrm{C}$ under nitrogen until use. Lenses were processed within three weeks of storage.

\section{Separation of Cortex and Nucleus}

During the extracapsular cataract surgery part of the outer cortex is lost, therefore we have chosen to compare only the nuclear region of both clear and cataractous lenses. Cortex was isolated from the nucleus as described before (Mota et al., 1992). Individual lenses were gently stirred at $4^{\circ} \mathrm{C}$ in $2.5 \mathrm{ml}$ of buffer (Buffer A) containing $50 \mathrm{~mm}$ Tris (hydroxymethyl) aminomethane (Tris), 5 mm ethylenediaminetetraacetic acid (EDTA), $10 \mathrm{~mm} \beta$-mercaptoethanol and $0.02 \%$ sodium azide $(\mathrm{pH} 7 \cdot 4)$. The nuclear material was considered as being approximately the inner one third of the total lens volume.

\section{Isolation of Lens Membranes}

Each lens nucleus was homogenized individually in $5 \mathrm{ml}$ of buffer $\mathrm{A}$ and the homogenates were pooled. Lens membranes were isolated as described elsewhere (Fernandes et al., 1996). Briefly, lens homogenates were centrifugated at $10000 \mathrm{~g}$ for $40 \mathrm{~min}$, the supernatant containing water soluble proteins was discarded. Urea soluble proteins were washed out from the resulting pellet by resuspension in $5 \mathrm{ml}$ per nucleus of $50 \mathrm{~mm}$ Tris- $\mathrm{HCl}$ and $7 \mathrm{~m}$ urea. The suspension was vortexed and diluted by further addition of $5 \mathrm{ml}$ of distilled water followed by centrifugation at $10000 \mathrm{~g}$ for $20 \mathrm{~min}$. The pellet was resuspended in $5 \mathrm{ml}$ per nucleus of buffer containing $10 \mathrm{~mm}$ Tris- $\mathrm{HCl}$ and $50 \mathrm{~mm} \mathrm{NaCl}$ and centrifuged at $10000 \boldsymbol{g}$ for $20 \mathrm{~min}$ to remove traces of urea. The resulting pellet was considered as the membrane fraction and was resuspended in $1.5 \mathrm{ml}$ per nucleus of the same buffer.

\section{Membrane Oxidation}

Membrane suspensions, obtained as described above, were oxidized by incubation with $10 \mathrm{~mm} \mathrm{AAPH}$ for $12 \mathrm{hr}$ at $37^{\circ} \mathrm{C}$. Controls were incubated under the same conditions but in the absence of AAPH.

\section{Total Lipid Extraction}

Membrane suspension $(1 \mathrm{ml})$ was first mixed with $50 \mu \mathrm{g}$ of 22-ketocholesterol, as internal standard for oxysterols determination. The mixture was then combined with $1.5 \mathrm{ml}$ sodium dodecyl sulfate (10 mM), $3 \mathrm{ml}$ ethanol and $3 \mathrm{ml}$ hexane. The mixture was stirred for $30 \mathrm{~min}$ at $4^{\circ} \mathrm{C}$ under nitrogen on a rotary stirrer. After $10 \mathrm{~min}$ centrifugation at $3000 \mathrm{~g}$, the organic layer was transferred to a glass vial. The solvent was evaporated under a stream of nitrogen at room temperature. The addition of BHT (final concentration $20 \mu \mathrm{M}$ ) to the samples at the beginning of the extraction procedure did not affect the results.

\section{Solid-phase Extraction}

Cholesterol oxides were isolated from cholesterol by a modification of a solid phase extraction procedure initially described for the isolation of oxysterols from egg yolk (Nourooz-Zadeh, 1990) with the following modifications. The samples, dissolved in $300 \mu \mathrm{l}$ of acetonitrile: 2 -propanol ( $1: 1$ by vol.), were applied on a C18 cartridge $(500 \mathrm{mg}$ ) prewashed with $3 \mathrm{ml}$ of 


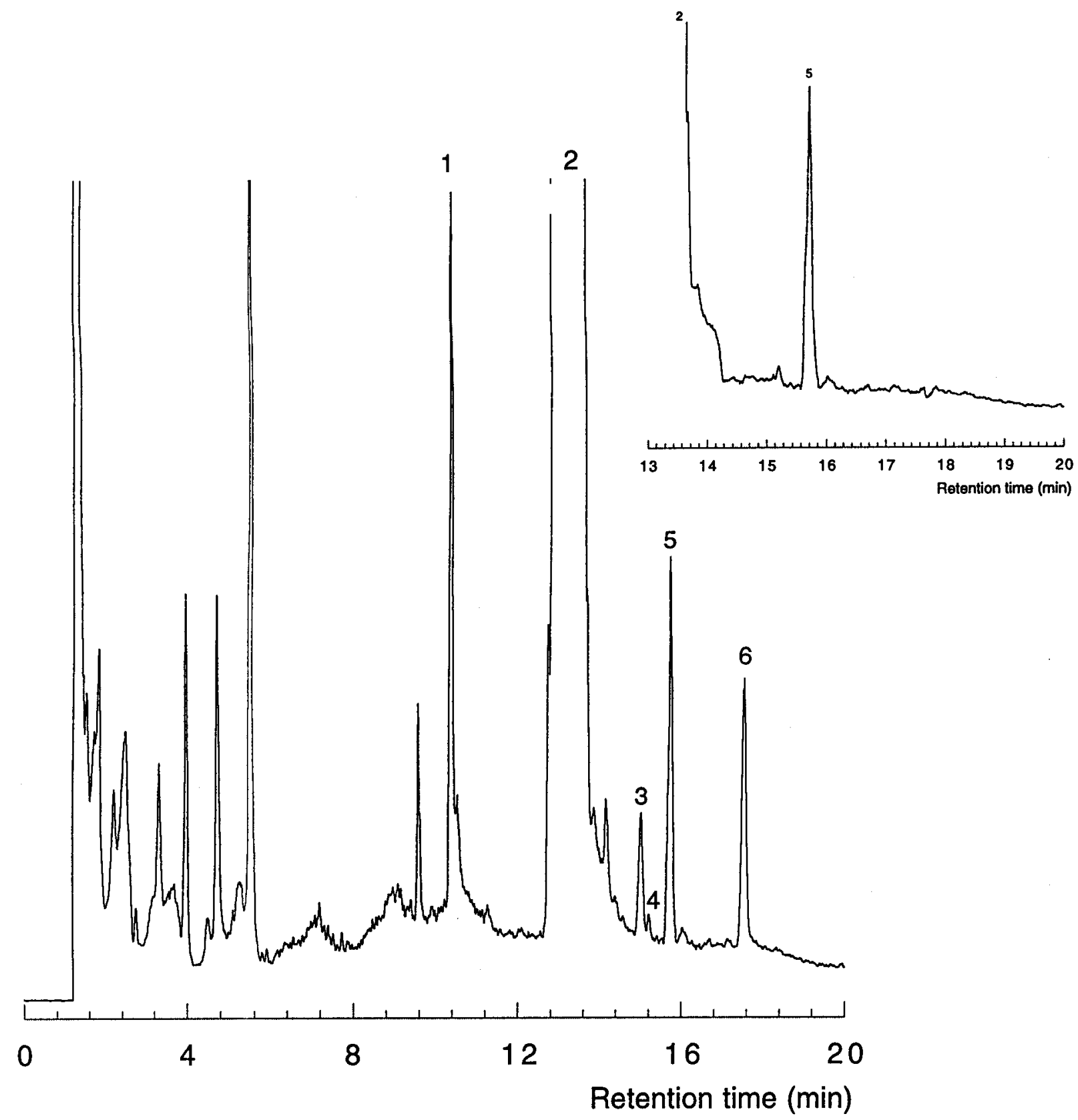

FIg. 1. Formation of cholesterol oxides after in vitro oxidation of clear human lens membranes $(n=5)$ with 10 mM AAPH for $12 \mathrm{hr}$ at $37^{\circ} \mathrm{C}$. Samples were diluted to the same phospholipid concentration. The total lipid extract was derivatized with BSTFA and the cholesterol and oxysterol ether derivatives were separated by GC. The insert represents the same separation for controls consisting of clear lens membranes incubated for $12 \mathrm{hr}$ at $37^{\circ} \mathrm{C}$ in the absence of AAPH. (1) $5 \alpha$-cholestane, (2) cholesterol, (3) $7 \beta$-hydroxycholesterol, (4) 5 $\alpha, 6 \alpha$-epoxycholestanol, (5) 22-ketocholesterol and (6) 7-ketocholesterol.

acetonitrile followed by $5 \mathrm{ml}$ of acetonitrile: 2propanol:water (55:25:20 by vol.). Oxysterols were eluted with $15 \mathrm{ml}$ of acetonitrile:2-propanol:water (55:25:20 by vol.). The organic solvent was removed under a stream of nitrogen.

A mixture of cholesterol plus several cholesterol oxides was extracted according to the same procedure as to control the extraction yield.

\section{Derivatization}

Immediately after evaporation of solvent to dryness, the lipid extract was incubated with $150 \mu \mathrm{l}$ of BSTFA.
The vial was sealed under nitrogen and incubated for $12 \mathrm{hr}$ at room temperature (as this was shown to improve the derivatization yield as compared to hot derivatization). The solvent was evaporated under nitrogen and the dried residue was reconstituted in $50 \mu \mathrm{l}$ of hexane containing $1 \%$ BSTFA.

\section{Gas-chromatography}

Cholesterol and oxysterols trimethyl ether derivatives were analysed by gas chromatography (GC) on a Dimension (TriMetrics Inc., Austin, Tex, U.S.A.) equipped with a flame ionization detector and a 
TABLE I

Formation of cholesterol oxides after oxidation of human lens membranes*

\begin{tabular}{lrr}
\hline Oxysterol & $\begin{array}{c}\text { Concentration } \\
\left(\mathrm{mmol} \mathrm{mol}^{-1}\right. \\
\text { cholesterol })\end{array}$ & \multicolumn{1}{c}{ Relative \% } \\
\hline $7 \alpha$-hydroxycholesterol & $8 \cdot 3( \pm 3 \cdot 71)$ & $6 \cdot 0( \pm 2 \cdot 72)$ \\
$7 \beta$-hydroxycholesterol & $25 \cdot 2( \pm 4 \cdot 98)$ & $18 \cdot 8( \pm 3 \cdot 71)$ \\
$5 \alpha, 6 \alpha$-epoxycholestanol & $1 \cdot 4( \pm 0 \cdot 61)$ & $1 \cdot 2( \pm 0 \cdot 53)$ \\
7 -ketocholesterol & $100 \cdot 5( \pm 7 \cdot 59)$ & $74 \cdot 0( \pm 5 \cdot 62)$ \\
\hline
\end{tabular}

* Quantitative determination of oxysterols is based both on relative retention time (with respect to 22-ketocholesterol) and on the pre-determined concentration dependent response curves for each sterol ether derivative.

splitless injector $(0.5 \mathrm{~min}$ splitless time). The sample $(1 \mu \mathrm{l})$ was injected onto a methylsilicon column (20 m $\times 0.2 \mathrm{~mm}$ I.D., film thickness $0 \cdot 25 \mu$; Chrompack, Middelburg, The Netherlands) using nitrogen as
TABLE II

Solid phase extraction yield $\dagger$

\begin{tabular}{lc}
\hline Oxysterol & Recovery $(\%)$ \\
\hline $7 \alpha$-hydroxycholesterol & $83 \cdot 6( \pm 4 \cdot 02)$ \\
$7 \beta$-hydroxycholesterol & $87 \cdot 7( \pm 3 \cdot 99)$ \\
$5 \alpha, 6 \alpha$-epoxycholestanol & - \\
22-ketocholesterol & $92 \cdot 5( \pm 1 \cdot 73)$ \\
20-hydroxycholesterol & $91 \cdot 7( \pm 3 \cdot 30)$ \\
25-hydroxycholesterol & $77 \cdot 5( \pm 3 \cdot 42)$ \\
membranes + standards & $71 \cdot 1( \pm 9 \cdot 27)$ \\
cholesterol +standards & $83 \cdot 9( \pm 3 \cdot 76)$ \\
\hline
\end{tabular}

$\dagger$ Data represent the mean $( \pm$ s.D. $)$ for recovery $\%$ of triplicates. Coefficient of variation associated with GC determinations is less than $2 \%$ and therefore was neglected.

the carrier gas. Initial column temperature was $200^{\circ} \mathrm{C}$ ( 2 min hold) and then programmed $10^{\circ} \mathrm{C} \mathrm{min}^{-1}$ to $280^{\circ} \mathrm{C}(10 \mathrm{~min}$ hold $)$. Detector temperature was $280^{\circ} \mathrm{C}$ and injector temperature was $250^{\circ} \mathrm{C}$.

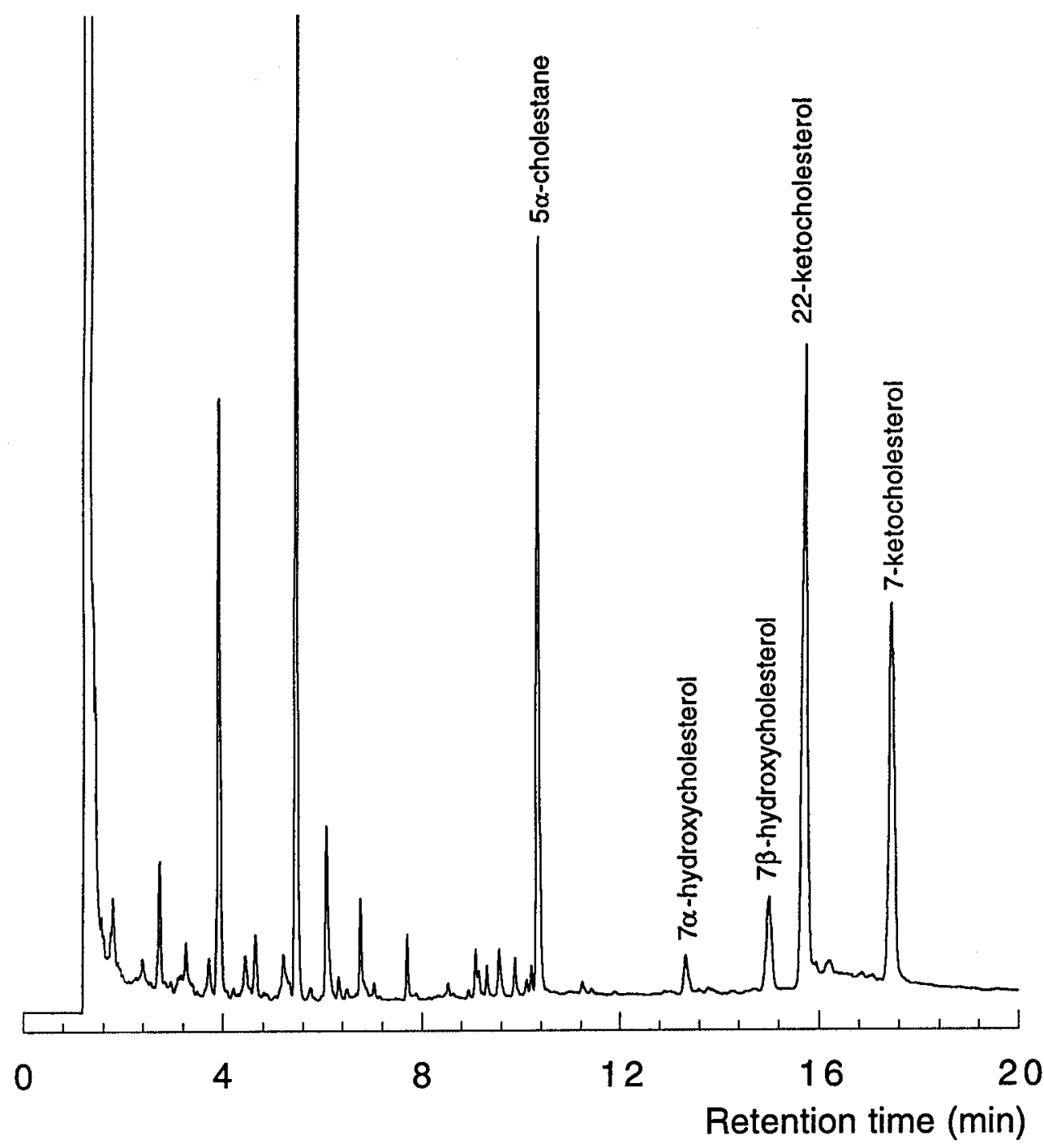

FIG. 2. Effect of solid phase extraction, on a $C_{18}$ column, on the separation of cholesterol oxides isolated from clear lens membranes oxidized with $10 \mathrm{~mm}$ AAPH. Experimental conditions are as described in legend to Fig. 1 and in Materials and Methods. 


\section{Determination of Phospholipid}

The phospholipid content was determined as inorganic phosphate according to Bartlett (1959).

\section{Results}

The first stage of this study consisted in establishing the oxidizability of cholesterol (5-cholesten- $3 \beta$-ol) present in lens membranes as well as in identifying the resulting oxidation products. Figure 1 and Table I show that after oxidation of membranes, obtained from transparent human lenses, with an azo-compound (AAPH), five major cholesterol oxides are formed: $7 \alpha$-hydroxycholesterol (5-cholestene-3 $\beta, 7 \alpha$ - diol), $\quad 7 \beta$-hydroxycholesterol $\quad(5$-cholestene- $3 \beta, 7 \beta$ diol), $5 \alpha, 6 \alpha$-epoxycholestanol $\quad(5,6 \alpha$-epoxy- $5 \alpha$-cholestan-3 $\beta$-ol) and 7 -ketocholesterol (5-cholesten-3 $\beta$ ol-7-one) (Table I). Not surprisingly most of this oxides result from cholesterol oxidation at position 7 , as C-7 carbon-centered and 7-peroxyl radicals are among the more stable oxysterols precursors (Smith, 1991b). It is noteworthy that the total amount of cholesterol oxides recovered after oxidation accounted for only one third of the total cholesterol decrease observed over the same period of time. No cholesterol oxides could be detected in non-oxidized controls of clear lens membranes (Fig. 1, insert). The formation of cholesterol oxides, following an oxidative insult, has been further confirmed by thin layer chromatography (data not

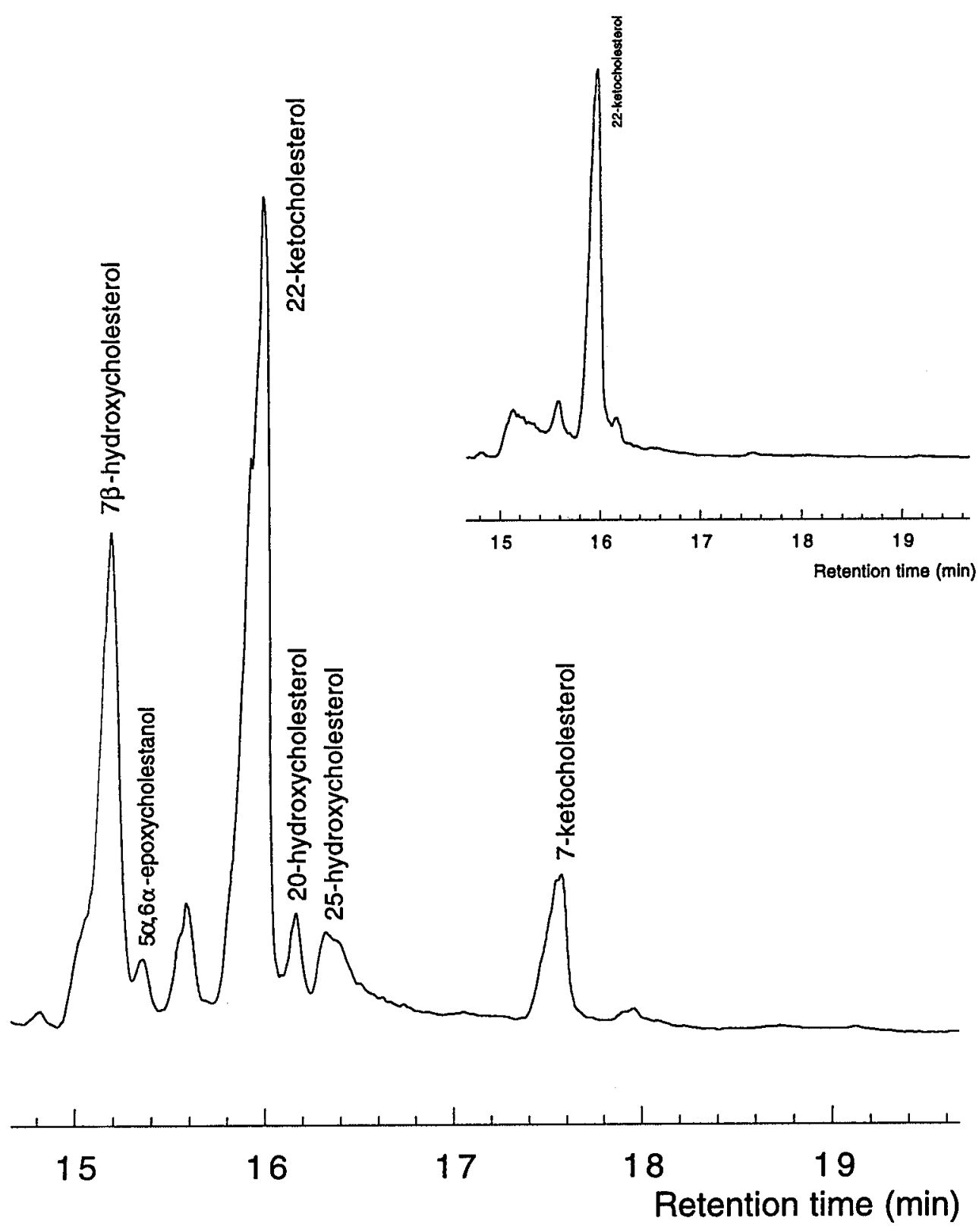

Fig. 3. Chromatographic separation of the major oxysterols ether derivatives present in membranes obtained from the nucleai of a pool of cataractous lenses $(n=6)$ and (insert) a pool of clear human lenses $(n=5)$. Both samples were diluted to the same phospholipid concentration. Lipids were extracted as described in Materials and Methods and oxysterols were concentrated on a solid phase $\mathrm{C}_{18}$ column. 
TABLE III

Major cholesterol oxides in human lensesł

\begin{tabular}{|c|c|c|c|c|}
\hline & \multicolumn{2}{|c|}{ Cataract } & \multicolumn{2}{|c|}{ Normal } \\
\hline & $\begin{array}{c}\text { Concentration } \\
\left(\mathrm{mmol} \mathrm{mol}^{-1}\right. \\
\text { Cholesterol })\end{array}$ & $\begin{array}{c}\text { Relative } \\
\text { abundance (\%) }\end{array}$ & $\begin{array}{c}\text { Concentration } \\
\left(\mathrm{mmol} \mathrm{mol}^{-1}\right. \\
\text { Cholesterol) }\end{array}$ & $\begin{array}{c}\text { Relative } \\
\text { abundance (\%) }\end{array}$ \\
\hline $7 \beta-\mathrm{OH}$ & $7 \cdot 3( \pm 0 \cdot 74)$ & $56 \cdot 1( \pm 5 \cdot 75)$ & $0 \cdot 4( \pm 0 \cdot 19)$ & $100( \pm 21 \cdot 3)$ \\
\hline epoxide & $0 \cdot 9( \pm 0 \cdot 16)$ & $6 \cdot 5( \pm 1 \cdot 43)$ & & N.D. \\
\hline $20-\mathrm{OH}$ & $0 \cdot 6( \pm 0 \cdot 13)$ & $4 \cdot 6( \pm 1 \cdot 22)$ & & N.D. \\
\hline $25-\mathrm{OH}$ & $0 \cdot 1( \pm 0 \cdot 02)$ & $1 \cdot 0( \pm 0 \cdot 19)$ & & N.D. \\
\hline 7-keto & $4 \cdot 2( \pm 0 \cdot 32)$ & $31 \cdot 8( \pm 2 \cdot 89)$ & & N.D. \\
\hline
\end{tabular}

$\neq$ Data represent the average + s.D. for 54 human senile cataracts and 48 clear lenses. Quantitative determination of oxysterols is based both on relative retention time (with respect to 22-ketocholesterol) and on the pre-determined concentration dependent response curves for each sterol ether derivative.

N.D. - Not detectable.

shown). Once the profile for cholesterol oxidation was established in vitro, the next step attempted to identify cholesterol oxides in human cataractous lenses. Given the relatively small (as compared to cholesterol) amounts of cholesterol oxides in membranes from human lenses, an important analytical step was the enrichment of samples in oxysterols and the elimination of cholesterol and other neutral polar lipids. In fact, very high amounts of cholesterol in the sample could overload the GC separation, making it difficult to quantify $7 \beta$-hydroxycholesterol and $5 \alpha, 6 \alpha$-epoxycholestanol.

An adaptation of the method initially described by Nourooz-Zadeh (Nourooz-Zadeh, 1990), allowed for a selective removal of cholesterol from cholesterol oxides (Fig. 2). The method is based on a solid phase extraction which retains cholesterol on a C18 column and the cholesterol oxides are eluted with acetonitrile/2-propanol/water. The extraction yield was between $70-90 \%$ as evaluated by the recovery of authentic cholesterol oxides standards and of biological samples contaminated with known amounts of cholesterol oxides (Table II).

The chromatogram represented in Fig. 3 and the data presented in Table III, show the accumulation of cholesterol oxides in human cataracts. The major cholesterol oxides in cataractous lenses were identified as follows (increasing RT): $7 \beta$-hydroxycholesterol, $5 \alpha, 6 \alpha$-epoxycholestanol, $20 \alpha$-hydroxycholesterol (5cholestene-3 $\beta, 20 \alpha$-diol), 25-hydroxycholesterol (5cholestene-3 $\beta, 25$-diol) and 7-ketocholesterol, the $7 \beta$ hydroxycholesterol being the predominant cholesterol oxide. All of the cholesterol oxides formed after in vitro oxidation of clear lens membranes (Fig. 2) are also found in human cataracts (Fig. 3), though with different relative abundance. The results represented in Table II, show that the total amount of cholesterol oxides (13.1 mmol mol ${ }^{-1}$ cholesterol) present in senile cataracts is not particularly high but it is significantly higher than the levels found in clear lenses. Transparent lenses present virtually undetectable levels of oxysterols (Fig. 3, insert). Only in very few samples it is possible to detect minor amounts of $7 \beta$-hydroxycholesterol (Table III).

\section{Discussion}

Despite its direct implications on lens opacification, the data presented in this study clearly shows that cholesterol does oxidize in vivo in human lenses and that five major oxidation products accumulate in cataractous lens: $7 \beta$-hydroxycholesterol, $5 \alpha, 6 \alpha$ epoxycholestanol, 20 $\alpha$-hydroxycholesterol, 25-hydroxycholesterol and 7-ketocholesterol.

It should be noted that the real values for cholesterol oxides in whole human lenses may somehow be slightly different because, as to facilitate comparison with cataractous lenses, only the nuclei were used and cholesterol/phospholipid ratio is known to increase in this region of the lens (Cenedella, 1985).

On the other hand, the chemistry of cholesterol oxidation is complex yielding over 80 oxidation products many of which (although minor components) are not detected by the present analytical approach. In fact, the total amount of cholesterol oxides formed after in vitro membrane oxidation accounts only for one third of the total cholesterol decrease. If the same chemical pathways occur in vivo with similar yields, then, based on data presented in Table III the total amount of oxidized cholesterol in cataractous lenses can be estimated in about $4 \%$.

Cholesterol can be readily oxidized by a variety of reactive oxygen species (Smith, 1990, 1996) yielding several products, some of which possess adverse biological effects (Smith, 1996). Analysis of such cholesterol oxides in biological samples has been often limited by the complexity and sometime unreliability of time-consuming methods (Sadeg et al., 1993; Smith, 1996). In this study we have adapted a solidphase extraction (Nourooz-Zadeh, 1990) to isolate cholesterol oxides from human cataracts. The results show that such method allows for an efficient 
(70-90\%) recovery of the oxysterols present in human lenses, allowing for simultaneous removal of cholesterol.

Although the lens has only small amounts of unsaturated fatty acids (Rosenfeld and Spector, 1982), the high concentration of cholesterol in lens membrane may provide an alternative target for oxidation.

There is now a substantial background information suggesting that oxidative stress could be a causative factor associated with cataract development (Spector, 1995). However the mechanism by which reactive oxygen species may exert deleterious effects to the lens have not yet been clearly elucidated. The evidence also show that disturbances in cholesterol homeostasis may result in cell damage by a variety of mechanisms (Cenedella, 1996). The implications of cholesterol oxidation in the lens (as in other tissues) are still largely unknown. Sterol oxidation in human cataracts has been evaluated in 1983 by Dillon et al. (Dillon et al., 1983) using HPLC separation of neutral lipids coupled with UV detection. Under the experimental conditions used, the authors did not find any detectable amount of cholesterol oxides in cataractous lenses. However, it is possible that very high levels of cholesterol and cholesterol esters present in cataract samples could 'dissolve' oxysterols that would coelute with cholesterol. In support of this view, is the observation that the extraction yield of each oxysterol significantly decreases in mixtures containing lens lipid extracts, whereas the extraction yield is not affected by the presence of high concentrations of cholesterol (Table I). The enrichment of the sample in oxysterols and selective retention of cholesterol after solid phase extraction is therefore considered a critical step in the present approach.

It is not obvious if, in the concentration found in human lenses, cholesterol oxides would present major noxious effects, nor is it known if accumulation of such oxysterols may account for senile cataract formation. The presence of cholesterol oxides at the concentrations found in cataracts could, for example, inhibit 3-HMG-coenzyme A reductase (Parish, Parish and $\mathrm{Li}, 1995)$. However such effects are only likely to interfere with cell viability and lens transparency if the cholesterol oxides are present during cell differentiation, when the rate of cholesterol synthesis must increase to cope with the remarkable enlargement of plasma membrane.

In other tissues, it has been shown that the activity of membrane ionic pumps is strongly dependent on cholesterol homeostasis (Vemuri and Philipson, 1989). By analogy, it is conceivable that similar changes in lens membranes could result in electrolytic imbalance disrupting, for example, calcium homeostasis, which could result in cataract formation by a plethora of possible mechanisms (Truscott, 1990).

Other indirect evidence suggest that cholesterol homeostasis is essential to keep the lens transparent. Several pathological conditions involving mutations in enzymes involved in cholesterol metabolism, such as Smith-Lemli-Opitz syndrome, cerebrotendinous xanthomatosis and mevalonic aciduria, all represent increased risk factors for cataract development which in many cases is one characteristic aspect associated with the condition (Cenedella, 1996). Several hypocholesterolemic drugs including simvastatin, pravastatin and lovastatin are potent inhibitors of 3-HMG CoA reductase (Sirtori, 1993) and may induce cataract both in animal models and in man (Cenedella, 1996).

The assumption that cholesterol oxidation is a stochastic, chemically destructive process may however underestimate the significance of its ubiquitous presence in living cells. It has been suggested in different contexts that cholesterol may act as an antioxidant (Smith, 1991a; 1996). Should this be the case in the lens, then the accumulation of small amounts of oxysterols in human cataracts could be purposeful (scavenging putative harmful oxidants) and reflect a cholesterol antioxidant role indicating, at the same time, an increased production of oxidants and/or a failure in the antioxidant protective systems of cataractous lens. Cholesterol would in this case act as a 'sacrificial' antioxidant protecting other membrane components. The high concentrations of cholesterol in the lens would enable it to perform a role in the lens comparable to that ascribed for albumin in the plasma (Halliwell, 1988).

In this study we have shown for the first time that cholesterol oxides accumulate in human cataracts. The physiological implications of such oxidation and its importance to cataract formation are still not clear and are areas under investigation in this Laboratory.

\section{Acknowledgements}

The authors are grateful to Dr Nourooz-Zadeh for valuable comments and suggestions to this study, specially regarding the solid phase extraction of cholesterol oxides.

This study was supported by a grant (PRAXIS/PSAU/ C/SAU/37/96) from Fundação para a Ciência e Tecnologia (FCT).

\section{References}

Bartlett, G. R. (1959). Phosphorus assay in column chromatography. J. Biol. Chem. 234, 466-8.

Bhuyan, K. C. and Bhuyan, D. K. (1984). Molecular mechanism of cataractogenesis: III. Toxic metabolites of oxygen as initiators of lipid peroxidation and cataract. Curr. Eye Res. 3, 67-81.

Cenedella, R. J. (1985). Regional distribution of lipids and phospholipase A2 Activity in normal and cataractous rat lens. Curr. Eye Res. 4, 113-20.

Cenedella, R. J. (1996). Cholesterol and cataracts. Surv. Ophthalmol. 40, 320-37.

Chylack, L. J., Lee, M., Tung, W. and Cheng, H. M. (1983). Classification of human senile cataractous change by the American Cooperative Cataract Research Group (CCRG) method. Invest. Ophthalmol. Vis. Sci. 24, 42431. 
Dillon, J., Mehlman, B., Pnticorvo, L. and Spector, A. (1983). The state of neutral lipids in normal and cataractous human lenses. Exp. Eye Res. 37, 91-8.

Duindam, J. J., Vrensen, G. F. J. M., Otto, C., Puppels, G. J. and Greve, J. (1995). New approach to assess the cholesterol distribution in the eye lens: confocal Raman spectroscopy and filipin cytochemistry. J. Lipid. Res. 36, 1139-46.

Fernandes, R., Pereira, P., Ramalho, J. S., Mota, M. C. and Oliveira, C. R. (1996). An experimental model for the evaluation of lipid peroxidation in lens membranes. Curr. Eye Res. 15, 395-402.

Garner, M. H., Roy, D., Rosenfeld, D., Garner, W. H. and Spector, A. (1981). Biochemical evidence for membrane disintegration in human cataract. Proc. Nat. Acad. Sci. U.S.A. 78, 1892-5.

Halliwell, B. (1988). Albumin: an important extracellular antioxidant. Biochem. Pharmacol. 37, 569-71.

Kabadi, U. M. (1988). Glycosylation of proteins: lack of influence of aging. Diabetes Care 11, 429-32.

Kamei, A. (1993). Glutathione levels of the human crystalline lens in aging and its antioxidant effect against the oxidation of lens proteins. Biol. Pharm. Bull. 16, 870-5.

L'vova, S. P., Gorbunova, T. F. and Abaeva, E. M. (1993). [The effect of hypothermia and dalargin on lipid peroxidation in rat tissues]. Vopr. Med. Khim. 39, 21-4.

Lerman, S. (1984). Biophysical aspects of corneal and lenticular transparency. Curr. Eye Res. 3, 3-14.

Lipman, R. M., Tripathi, B. J. and Tripathi, R. C. (1988). Cataracts induced by microwave and ionizing radiation. Surv. Ophthalmol. 33, 200-10.

Mota, M. C., Ramalho, J. S., Carvalho, P., Quadrado, J. and Baltar, A. S. (1992). Monitoring in vivo lens changes. A comparative study with biochemical analysis of protein aggregation. Doc. Ophthalmol. 82, 287-96.

Nourooz-Zadeh, J. (1990). Determination of the autoxidation products from free or total cholesterol: a new multistep enrichment methodology including the enzymatic release of esterified cholesterol. J. Agric. Food Chem. 38, 1667-73.

Ohrloff, C. and Hockwin, O. (1984). Superoxide dismutase (SOD) in normal and cataractous human lenses. Graefe's Arch. Clin. Exp. Ophthalmol. 222, 79-81.

Parish, E. J., Parish, S. C. and Li, S. (1995). Side-chain oxysterol regulation of 3-hydroxy-3-methylglutaryl coenzyme A reductase activity. Lipids 30, 247-51.
Rosenfeld, L. and Spector, A. (1982). Comparison of polynsaturated fatty acid levels in normal and mature cataractous human lenses. Exp. Eye Res. 35, 69-75.

Sadeg, N., Pham, H. C., Martin, C., Warnet, J. M. and Claude, J. R. (1993). Effect of cyclosporin A and its metabolites and analogs on lipid peroxidation in rabbit renal microsomes. Drug Chem. Toxicol. 16, 165-74.

Sirtori, C. R. (1993). Tissue selectivity of hydroxymethylglutaryl coenzyme A (HMG CoA) reductase inhibitors. Pharmacol. Ther. 60, 431-59.

Smith, L. L., Kulig, M. J. and Teng, J. I. (1977). On the failure of superoxide radical anion to react with cholesterol. Chem. Phys. Lipids 20, 211-15.

Smith, L. L. (1987). Cholesterol autoxidation 1981/86. Chem. Phys. Lipids 44, 87-125.

Smith, L. L. (1990). Mechanisms of formation of oxysterols: a general survey. In Free radicals, lipoproteins, and membrane lipids. Crastes de Paulet, A., Douste Blazy, L. and Paoletti, R. eds), Pp. 115-32. Plenum Publishing Corp.: New York, U.S.A.

Smith, L. L. (1991a). Another cholesterol hypothesis: cholesterol as antioxidant. Free Rad. Biol. Med. 11, 47-61.

Smith, L. L. (1991b). Cholesterol oxidation. In Membrane lipid oxidation (Vigo-Pelfrey, C. ed.), Pp. 129-54. CRC Press: Boca Raton, U.S.A.

Smith, L. L. (1996). Review of progress in sterol oxidations: 1987-1995. Lipids 31, 453-587.

Smith, L. L. and Johnson, B. H. (1989). Biological activities of oxysterols. Free Rad. Biol. Med. 7, 285-332.

Spector, A. (1984). The search for a solution to senile cataracts. Proctor lecture. Invest. Ophthalmol. Vis. Sci. 25, 130-46.

Spector, A. (1995). Oxidative stress-induced cataract: mechanism of action. FASEB J. 9, 1173-82.

Spector, A. and Garner, W. H. (1981). Hydrogen peroxide and human cataract. Exp. Eye Res. 33, 673-81.

Spector, A. and Roy, D. (1978). Disulfide linked high molecular weight protein associated with human cataract. Proc. Nat. Acad. Sci. U.S.A. 75, 3244-8.

Truscott, R. J. W., Marcantonio, J. M., Tomlinson, J. and Duncan, G. (1990). Calcium induced opacification and proteolysis in the intact rat lens. Invest. Ophthalmol. Vis. Sci. 31, 2405-11.

Vemuri, R. and Philipson, K. D. (1989). Influence of sterols and phospholipids on sarcolemmal and sarcoplasmic reticular cation transporters. J. Biol. Chem. 264, 8680-5.

Zelenka, P. S. (1984). Lens lipids. Curr. Eye Res. 3, 1337-59. 